\title{
Multisystem Inflammatory Syndrome in Children, Chile, May-August 2020
}

Carmen Niño-Taravilla, Hugo Otaola-Arca, Natalie Lara-Aguilera, Yuri Zuleta-Morales, Paula Ortiz-Fritz

We describe 26 children with multisystem inflammatory syndrome associated with coronavirus disease in the pediatric intensive care unit of Roberto del Río Hospital (Santiago, Chile). In total, $10(38.5 \%)$ children required mechanical ventilation; $13(50.0 \%)$ required inotropic support. In addition, 18 (69.2\%) patients had echocardiographic abnormalities. No patients died.

$\mathrm{O}$ n March 11, 2020, the World Health Organization declared a coronavirus disease (COVID-19) pandemic. Acute respiratory failure is the most common complication of COVID-19 in adults (1); as of February 2021, COVID-19 has been associated with 2.4 million deaths according to the World Health Organization (https://www.who. int/publications/m/item/weekly-epidemiologicalupdate---23-february-2021). Most children and adolescents with COVID-19 have mild disease that does not require medical intervention (2).

In April 2020, a total of 8 previously healthy children with hyperinflammatory shock in the United Kingdom tested positive for antibodies against severe acute respiratory syndrome coronavirus 2 (SARS-CoV-2), the causative agent of COVID-19 (3). Consequently, the Royal College of Pediatrics and Child Health proposed the diagnosis of multisystem inflammatory syndrome associated with COVID-19 in children (MIS-C), defined as a persistent fever, inflammation, and evidence of organ dysfunction, after the exclusion of any other microbial cause, with or without PCR confirmation of SARS-CoV-2 infection (4). On May 14, 2020, the US Centers for Disease Control and Prevention issued an advisory for

Author affiliations: Clinica INDISA, Santiago, Chile

(C. Niño-Taravilla); Hospital Roberto del Río, Santiago

(C. Niño-Taravilla, N. Lara-Aguilera, Y. Zuleta-Morales,

P. Ortiz-Fritz); Clinica Alemana de Santiago, Santiago

(H. Otaola-Arca)

DOI: https://doi.org/10.3201/eid2705.204591
MIS-C; the same day, the World Health Organization also issued a report with a case definition of MIS-C (https:/ / emergency.cdc.gov/han/2020/han00432. asp). Researchers have since reported similar cases in the United States (5) and Europe (6-9). The signs and symptoms of MIS-C can resemble Kawasaki disease, toxic shock syndrome, hemophagocytic lymphohistiocytosis, and macrophage activation syndrome (10).

Few publications on COVID-19 in children (11) and MIS-C (12) have reviewed cases in Latin America. We describe the clinical characteristics, treatment, and results of a cohort of children admitted to the pediatric intensive care unit (PICU) with MIS-C in a tertiary hospital in Chile.

\section{The Study}

We analyzed patients with MIS-C treated in the PICU of Roberto del Río Hospital (Santiago, Chile) during May 11-August 30, 2020 (Figure). We used the case definition of MIS-C proposed by the Ministry of Public Health of Chile (13).

We collected demographic data, medical history, clinical symptoms, and physical examination findings, as well as results of imaging, cardiac, and laboratory tests conducted during the patient's stay in the emergency room and PICU. We also analyzed data on treatment, complications, outcome, and length of PICU and total hospital stay. The institutional ethics committee of Roberto del Rio Hospital approved the study protocol. We described categorical variables with absolute frequencies and percentages; we described continuous variables with medians and IQRs.

Of the 33 patients with SARS-COV-2 who were hospitalized in the PICU during the study period, 26 met the definition for MIS-C. In total, $16(61.5 \%)$ of these 26 patients met the criteria for Kawasaki disease. The median age was 6.5 years (IQR 2-10.5 years); 15 (57.7\%) patients were male. Only 1 patient had a chronic underlying condition (Table 1 , https:/ / wwwnc.cdc.gov/EID/ article/27/5/20-4591-T1.htm) (14). 
Children and adolescents $0-9$ years old with fever $>3$ days with $\geq 2$ of the following criteria:

- Bilateral nonsuppurative rash, conjunctivitis, or mucocutaneous involvement

- Hypotension or shock

- Myocardial dysfunction, pericardidtis, valvulitis, coronary abnormalities (echocardiographic data), or elevation of myocardia damage parameters (troponins or Pro-BNP)

- Coagulopathy (PT or APTT alterations, D-dimer elevation [>1,000 $\mu \mathrm{g} / \mathrm{mL}]$ )

- Gastrointestinal involvement (vomiting, diarrhea, or abdominal pain)

and

Elevation of CRP $>50 \mathrm{mg} / \mathrm{L}$ or $\mathrm{PCT}>1 \mathrm{ng} / \mathrm{dL}$

and

Without other provable eitiologies that explain the case

and

Evidence of COVID-19 infection (PCR positive for SARS-CoV-2, serologic or epidemiologic link)

Shock, cardiovascular involvement, or KD criteria

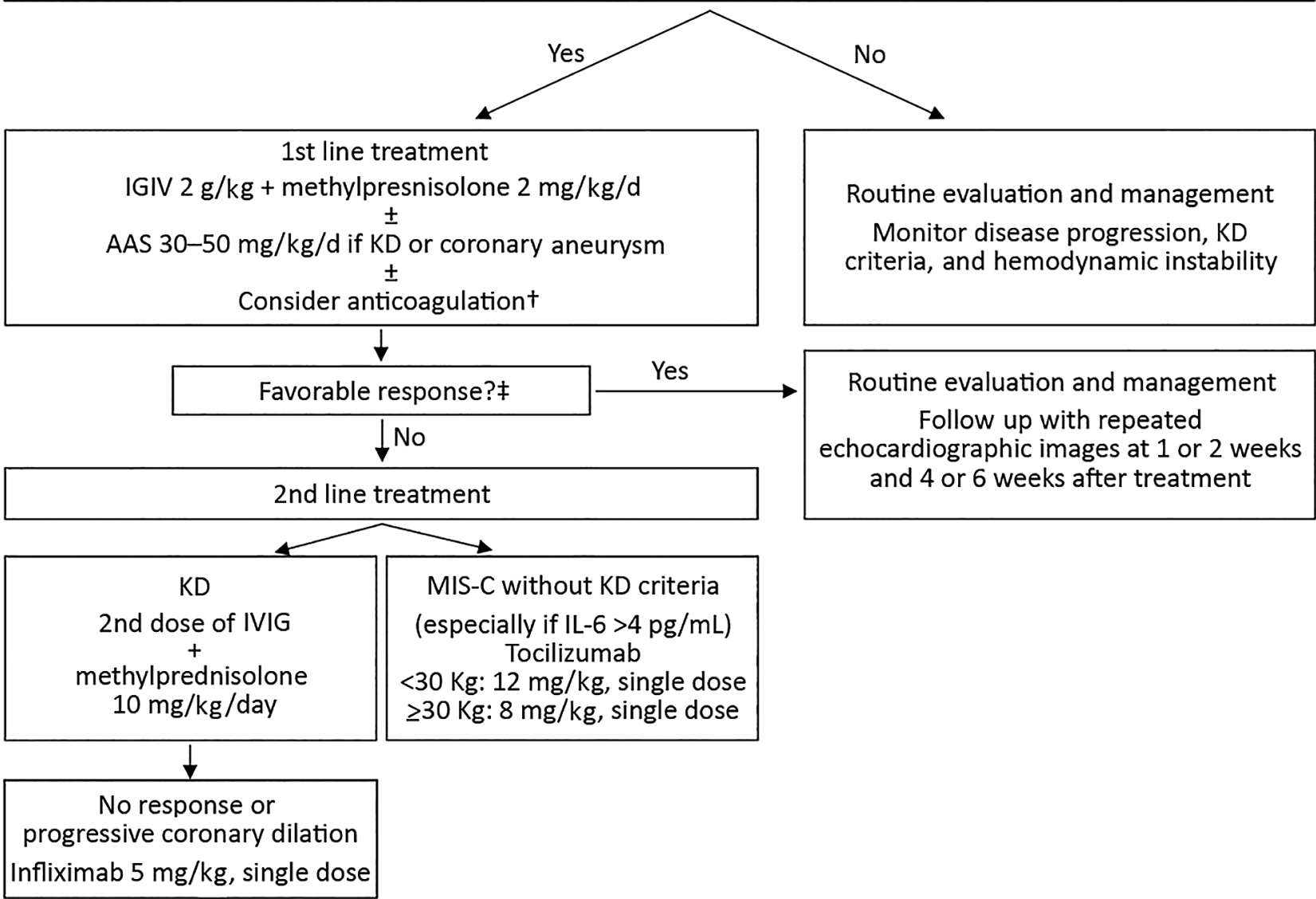

Figure. Treatment algorithm for children with multisystem inflammatory syndrome associated with COVID-19, Chile, May-August 2020. †Prophylactic anticoagulation was considered if D-dimer was $>1,000 \mathrm{ng} / \mathrm{dL}$ or progressively increasing: treatment was 1 $\mathrm{mg} / \mathrm{kg} / \mathrm{d}$ of low molecular weight heparin (Enoxaparin). When thrombosis was suspected or confirmed, the dose was increased to $1 \mathrm{mg} / \mathrm{kg}$ every 12 hours and adjusted with anti-Xa factor activity. ‡Favorable response was considered absence of fever for 48 hours, hemodynamic stability, and improvement of inflammatory parameters. AAS, acetylsalicylic acid; APTT, activated partial thromboplastin time; COVID-19, coronavirus disease; CRP, C-reactive protein; IVIG, intravenous immunoglobulin; KD, Kawasaki disease; MIS-C, pediatric inflammatory multisystem syndrome temporally associated with coronavirus disease; PCT, procalcitonin; pro-BNP, pro-brain natriuretic peptide; PT, prothrombin time; SARS-CoV-2, severe acute respiratory syndrome coronavirus 2. 
In total, $22(84.6 \%)$ patients tested positive for SARS-CoV-2 infection, 7 (26.9\%) by reverse transcription PCR and 15 (57.6\%) by serologic assay. The other $4(15.3 \%)$ patients tested negative for SARS-CoV-2 but had a COVID-19 exposure. The most frequent symptoms were fever $(26,100 \%)$, shock $(24,92.3 \%)$, abdominal pain $(17,65.4 \%)$, diarrhea $(16,61.5 \%)$, vomiting $(12,46.2 \%)$, rash $(16,61.5 \%)$, and conjunctivitis (15, $57.7 \%$ ) (Table 1 ).

We also collected data on laboratory test values (Table 2), critical care interventions, treatments, and outcomes (Table 1$)$. Ten (38.5\%) patients required mechanical ventilation for a median duration of 4 days (IQR 2.5-5 days). Only 1 (3.8\%) patient met the criteria for acute respiratory distress syndrome; that patient had an oxygenation index of 25 . Half (13, $50.0 \%$ ) of the patients required vasoactive drugs. We used high-flow hemofiltration as salvage therapy for refractory shock in 1 patient. No patients required extracorporeal membrane oxygenation (ECMO). In total, $20(76.9 \%)$ patients received intravenous immunoglobulin; $2(9.1 \%)$ received a second dose. We treated $23(88.5 \%)$ patients with corticosteroids; 1 $(3.8 \%)$ required a larger dose (Figure). We prescribed immunomodulatory agents for $4(15.4 \%)$ patients: tocilizumab for 3 patients and infliximab for 1 .

In total, 18 (69.2\%) patients had echocardiographic abnormalities (Table 1), including 5 (19.2\%) patients who met the criteria for Kawasaki disease with coronary artery abnormalities. The median duration of PICU stay was 5 days (IQR 2-7 days). None of the patients died.

\section{Conclusions}

We describe 26 MIS-C patients in the PICU of Roberto del Río Hospital in Chile. In this hospital, the maximum incidence of MIS-C occurred $\approx 4$ weeks after the peak of COVID-19 cases in adults, as described in the literature (5-9).

The median age of the cohort in our study was 6.5 years, lower than usually reported for patients with MIS-C (8-9 years) (5); 2 patients were neonates. Slightly more than half (61.5\%) of patients met criteria for typical or atypical Kawasaki disease.

Nearly all $(84.6 \%)$ patients had laboratory-confirmed SARS-CoV-2 infection. However, whereas many $(57.6 \%)$ had antibodies against SARS-CoV-2, only $7(26.9 \%)$ tested positive by PCR. These findings suggest that MIS-C might be caused by a hyperinflammatory response after asymptomatic SARSCoV-2 infection, rather than direct cell injury from active viral replication. Although the syndrome's pathophysiology has been correlated with the cytokine storm described in adults with severe COVID-19 (13), the mechanisms of MIS-C remain unclear.

We observed clinical manifestations similar to those described internationally (5-9). In this cohort, the most frequent manifestation was fever with gastrointestinal symptoms $(65.4 \%)$, in agreement with findings described in the literature (8).

Similar to previous reports (5-9), our results showed almost all patients had cardiovascular involvement: $92 \%$ had shock and 50\% required vasoactive support. Although Roberto del Río Hospital is a

Table 2. Laboratory test values of 26 children with multisystem inflammatory syndrome associated with coronavirus disease, Chile, May-August 2020*

\begin{tabular}{|c|c|c|c|}
\hline \multirow[b]{2}{*}{ Test } & \multicolumn{2}{|c|}{ Median value (IQR) } & \multirow[b]{2}{*}{ Reference range } \\
\hline & Emergency department & Intensive care unit & \\
\hline Leukocytes, $\mathrm{mm}^{3}$ & $10,540.0(7,400.0-15,900.0)$ & NA & $4,500-11,000$ \\
\hline Lymphocytes, $\mathrm{mm}^{3}$ & $1,080.0(732.5-2,579.5)$ & $560.5(409.5-943.0)$ & $1,500-4,000$ \\
\hline Platelets, $\mathrm{mm}^{3}$ & $175,000.0(96,000.0-232,000.0)$ & $82,000.0(40,000.0-111,250.0)$ & $150,000-400,000$ \\
\hline Albumin, g/dL & $3.1(2.9-3.4)$ & $2.2(2.0-2.8)$ & $3.4-5.4$ \\
\hline Troponins, ng/mL† & NA & $0.1(0.0-1.8)$ & $<0.034$ \\
\hline Creatine phosphokinase, U/L & $133.5(55.5-234.0)$ & $100.0(162.5-220.5)$ & $32-294$ \\
\hline Creatinine kinase-MB, U/L & $2.2(1.1-11.9)$ & $3.3(1.2-13.4)$ & $<12$ \\
\hline C-reactive protein, $\mathrm{mg} / \mathrm{L}$ & $134.0(94.0-300.5)$ & $198.5(121.5-302.8)$ & $<5$ \\
\hline Procalcitonin, ng/mL† & NA & $13.0(2.39-38.0)$ & $<0.5$ \\
\hline Ferritin, ng/mL & $206.5(91.5-368.8)$ & $567.0(304.5-1000.0)$ & $15-150$ \\
\hline Triglycerides, mg/dL & $175.5(103.0-244.5)$ & $205.5(151.5-316.0)$ & $<75$ \\
\hline Lactate dehydrogenase, U/L & $288.0(257.0-357.0)$ & $285.5(261-328.3)$ & 105-333 \\
\hline Glutamic oxaloacetic transaminase, U/L & $45.0(32.0-66.0)$ & $51.0(36.5-66.0)$ & $0-40$ \\
\hline Fibrinogen, mg/mL & $457.0(375.0-513.0)$ & $447.0(353.25-509.0)$ & $200-400$ \\
\hline D-dimer, ng/mL & $1,700.0(730.0-3,500.0)$ & $2,900.0(1,670.0-3,950.0)$ & $<500$ \\
\hline Creatinine, $\mathrm{mg} / \mathrm{dL}$ & $0.6(0.4-1.2)$ & $0.8(0.5-1.5)$ & Varies $\ddagger$ \\
\hline Type B natriuretic pro-peptide, $\mathrm{pg} / \mathrm{mL} \S$ & NA & $1,749.0(255.8-4,722.8)$ & $<125$ \\
\hline Interleukin $6, \mathrm{~g} / \mathrm{mL}$ & NA & $322.0(95.5-621.8)$ & $<3.4$ \\
\hline
\end{tabular}


national reference center for ECMO, none of the patients in this cohort required extracorporeal supportive treatment; in contrast, Radia et al. (15) found that $4 \%$ of patients with MIS-C needed ECMO. This difference might be attributable to early immunotherapy.

Approximately two thirds (69.2\%) of patients had echocardiographic abnormalities. The most frequent $(26.9 \%)$ anomaly was left ventricular dysfunction with or without pericardial effusion. In all affected patients, cardiac function recovered before discharge from the PICU. Only 5 (19.2\%) of our patients had coronary abnormalities: 4 had a coronary dilatation (Z-score of $\approx 2.5-2.8$ ) and 1 had a medium coronary aneurysm (Zscore of 6). The frequency of coronary involvement is also consistent with previous reports (5-9).

We treated nearly all children with intravenous immunoglobulin $(76.9 \%)$ or corticosteroids $(88.5 \%)$. Treatment seemed to improve symptoms and decrease inflammatory responses, similar to findings in Europe and the United States (5-9). According to our treatment protocol, we administered tocilizumab to $3(11.7 \%)$ children; we administered infliximab to 1 $(3.8 \%)$ child with a medium coronary aneurysm. The main limitations of this study are small sample size and descriptive, nonrandomized design.

In conclusion, we described 26 children with MIS-C in Chile. Our findings were similar to those reported in other countries. Most patients had echocardiographic abnormalities, and half required vasoactive drug support. We administered immunomodulatory therapy to most patients. Clinical trials and long-term follow-up are needed to elucidate the mechanisms of various treatments and potential sequelae of this condition.

\section{Acknowledgments}

We thank all the health professionals in the pediatric intensive care unit of Roberto del Río Hospital (Santiago, Chile). We also thank the COVID-19 Committee of Roberto del Río Hospital.

\section{About the Author}

Dr. Niño-Taravilla is a pediatric intensivist at the PICU of Hospital Roberto del Río and Clínica Indisa in Santiago, Chile. Her research interests include sepsis and viral infection.

\section{References}

1. Fu L, Wang B, Yuan T, Chen X, Ao Y, Fitzpatrick T, et al. Clinical characteristics of coronavirus disease 2019 (COVID-19) in China: a systematic review and metaanalysis. J Infect. 2020;80:656-65. https:/ / doi.org/10.1016/ j.jinf.2020.03.041
2. Ludvigsson JF. Systematic review of COVID-19 in children shows milder cases and a better prognosis than adults. Acta Paediatr. 2020;109:1088-95. https://doi.org/10.1111/ apa.15270

3. Riphagen S, Gomez X, Gonzalez-Martinez C, Wilkinson N, Theocharis P. Hyperinflammatory shock in children during COVID-19 pandemic. Lancet. 2020;395:1607-8. https:/ /doi.org/ 10.1016/S0140-6736(20)31094-1

4. Royal College of Paediatrics and Child Health. Guidance: paediatric multisystem inflammatory syndrome temporally associated with COVID-19. 2020 [cited 2020 Aug 30]. https:/ / www.rcpch.ac.uk/sites/default/files/2020-05/ COVID-19-Paediatric-multisystem-\%20inflammatory\%20 syndrome-20200501.pdf

5. Feldstein LR, Rose EB, Horwitz SM, Collins JP, Newhams MM, Son MBF, et al.; Overcoming COVID-19 Investigators; CDC COVID-19 Response Team. Multisystem inflammatory syndrome in U.S. children and adolescents. N Engl J Med. 2020;383:334-46. PubMed https:/ / doi.org/10.1056/ NEJMoa2021680

6. Verdoni L, Mazza A, Gervasoni A, Martelli L, Ruggeri M, Ciuffreda M, et al. An outbreak of severe Kawasaki-like disease at the Italian epicentre of the SARS-CoV-2 epidemic: an observational cohort study. Lancet. 2020;395:1771-8. PubMed https://doi.org/10.1016/S0140-6736(20)31103-X

7. Toubiana J, Poirault C, Corsia A, Bajolle F, Fourgeaud J, Angoulvant F, et al. Kawasaki-like multisystem inflammatory syndrome in children during the covid-19 pandemic in Paris, France: prospective observational study. BMJ. 2020;369:m2094. PubMed https://doi.org/10.1136/ bmj.m2094

8. Cabrero-Hernández M, García-Salido A, Leoz-Gordillo I, Alonso-Cadenas JA, Gochi-Valdovinos A, González Brabin A, et al. Severe SARS-CoV-2 infection in children with suspected acute abdomen: a case series from a tertiary hospital in Spain. Pediatr Infect Dis J. 2020;39:e195-8. https:/ / doi.org/10.1097/INF.0000000000002777

9. Whittaker E, Bamford A, Kenny J, Kaforou M, Jones CE, Shah P, et al.; PIMS-TS Study Group and EUCLIDS and PERFORM Consortia. Clinical characteristics of 58 children with a pediatric inflammatory multisystem syndrome temporally associated with SARS-CoV-2. JAMA. 2020;324:259-69. https://doi.org/10.1001/jama.2020.10369

10. Nakra NA, Blumberg DA, Herrera-Guerra A, Lakshminrusimha S. Multi-system inflammatory syndrome in children (MIS-C) following SARS-CoV-2 infection: review of clinical presentation, hypothetical pathogenesis, and proposed management. Children (Basel). 2020;7:69. https://doi.org/10.3390/children7070069

11. Prata-Barbosa A, Lima-Setta F, Santos GRD, Lanziotti VS, de Castro REV, de Souza DC, et al.; Brazilian Research Network in Pediatric Intensive Care, (BRnet-PIC). Pediatric patients with COVID-19 admitted to intensive care units in Brazil: a prospective multicenter study. J Pediatr (Rio J). 2020;96:582-92. https://doi.org/10.1016/j.jped.2020.07.002

12. Torres JP, Izquierdo G, Acuña M, Pavez D, Reyes F, Fritis A, et al. Multisystem inflammatory syndrome in children (MIS-C): report of the clinical and epidemiological characteristics of cases in Santiago de Chile during the SARS-CoV-2 pandemic. Int J Infect Dis. 2020;100:75-81. https://doi.org/10.1016/j.ijid.2020.08.062

13. Minesterio de Salud. Protocolo Síndrome Inflamatorio Multisistémico en niños, niñas y adolescentes con SARS-CoV-2. 2020 [cited 2021 March 4]. https:/ / www.minsal.cl/wp-content/uploads/2020/07/ Si \%CC\%81ndromeInflamatorio-Multisiste\%CC\%81mico.pdf 
14. McCrindle BW, Rowley AH, Newburger JW, Burns JC, Bolger AF, Gewitz M, et al.; American Heart Association Rheumatic Fever, Endocarditis, and Kawasaki Disease Committee of the Council on Cardiovascular Disease in the Young; Council on Cardiovascular and Stroke Nursing; Council on Cardiovascular Surgery and Anesthesia; and Council on Epidemiology and Prevention. Diagnosis, treatment, and long-term management of Kawasaki disease: a scientific statement for health professionals from the American Heart Association. Circulation. 2017;135:e927-99. https://doi.org/10.1161/CIR.0000000000000484
15. Radia T, Williams N, Agrawal P, Harman K, Weale J, Cook J, et al. Multi-system inflammatory syndrome in children \& adolescents (MIS-C): a systematic review of clinical features and presentation. Paediatr Respir Rev. 2020 Aug 11 [Epub ahead of print]. https://doi.org/10.1016/j.prrv.2020.08.001

Address for correspondence: Carmen Niño-Taravilla, Pediatric Intensive Care Unit, Roberto del Rio Children Hospital, Av. Profesor Zañartu 1085, Independencia, Región Metropolitana, Chile; email: carmen.nino@hotmail.com

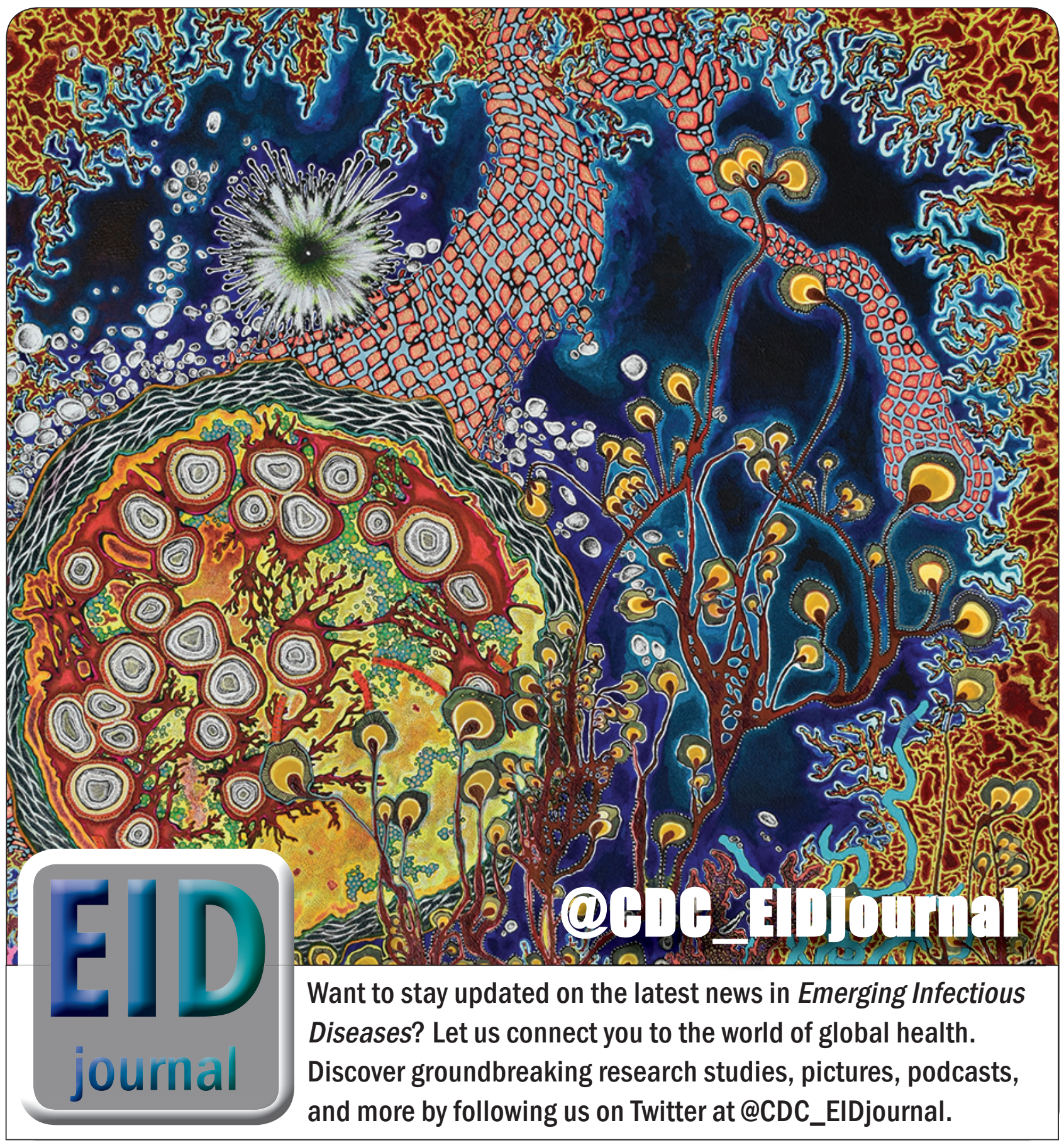

